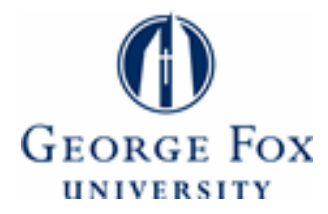

Digital Commons@ George Fox University

Faculty Publications - School of Physical Therapy

School of Physical Therapy

$3-2008$

\title{
Functional Rehabilitation Exercise Prescription for Golfers
}

Jason Brumitt

George Fox University, jbrumitt@georgefox.edu

R. Barry Dale

Follow this and additional works at: http://digitalcommons.georgefox.edu/pt_fac

Part of the Physical Therapy Commons

\section{Recommended Citation}

Published in Athletic Therapy Today, 2008; 13(2): 37-41 https://www.researchgate.net/journal/

1078-7895_Athletic_Therapy_Today

This Article is brought to you for free and open access by the School of Physical Therapy at Digital Commons @ George Fox University. It has been accepted for inclusion in Faculty Publications - School of Physical Therapy by an authorized administrator of Digital Commons@ George Fox

University. For more information, please contact arolfe@georgefox.edu. 


\title{
Functional Rehabilitation Exercise Prescription for Golfers
}

\author{
Jason Brumitt, PT • Pacific University and R. Barry Dale, PhD, PT, ATC, CSCS • \\ University of Tennessee at Chattanooga
}

AMATEUR and professional golfers are at risk for injuries to the low back, shoulders, elbows, wrists and hands, and the knees. ${ }^{1}$ The lumbar spine is particularly susceptible to injury, due to the shear, compression, rotation, and lateral bending forces created during each golf swing. ${ }^{1,2}$ The combination of these forces contributes to golfers experiencing more

\section{KEY POINTS}

Successful return of a golfer with low back pain to sport depends on identification of core dysfunctions and implementation of exercises that address them.

A comprehensive rehabilitation approach for golfers with low back pain should

include the prescription of functional core exercises

Referral to a professional golf instructor may be necessary to eliminate faulty swing mechanics that contribute to back pain injuries to the low back than any other region of the body. ${ }^{1-3}$ The golfer's lumbar spine experiences compressive loads during each swing that are approximately 8 times one's bodyweight. $^{2}$

The purpose of this report is to present a functional rehabilitation program for golfers who have chronic low back pain (LBP). Athletic trainers and therapists should consider the patient's preinjury fitness level and strength and conditioning training habits, as well as the forces exerted upon the lumbar spine by the multiplanar nature of the golf swing, when prescribing rehabilitative exercises. $^{4}$

\section{Potential Risk Factors}

Research evidence and clinical experience suggest that golfers who suffer from LBP demonstrate dysfunctional trunk flexibility and inadequate core strength and endurance. ${ }^{5-7}$ There are a few published research reports that have identified predictors of low back injury in golfers. ${ }^{5-8}$ Hypomobility has been reported among golfers with LBP. ${ }^{7.9} \mathrm{Vad}$ et al. ${ }^{7}$ conducted a cross-sectional study of hip and spine range of motion in both healthy and previously injured male golfers. Golfers who had previously experienced LBP (for a period of at least 2 weeks) demonstrated a statistically significant association between injury occurrence and decreased lead hip internal rotation, decreased lead hip FABERE distance (FABERE position measurement of the distance from the knee to table surface), and decreased lumbar extension. ${ }^{7}$ A golfer with an inadequate amount of lead hip internal rotation will compensate during the golf swing by excessively rotating through the lumbar spine. This compensatory swing pattern increases the stress imposed on the lumbar spine, especially if spinal mobility is limited. Golfers with LBP have also demonstrated increased trunk flexion at ball address and excessive leading side flexion during the backswing. ${ }^{9}$ 
When a golfer sustains a low back injury, muscle inhibition associated with the injury does not necessarily resolve with the cessation of LBP. ${ }^{10-12}$ Golfers with LBP have been found to have difficulty activating the transverse abdominis (TrA) muscle. ${ }^{5}$ Evans et al. ${ }^{5}$ evaluated the endurance capacity of the TrA muscle in 20 male golfers with a history of LBP and found that it was significantly lower than that measured in a cohort of golfers who had no history of back pain. ${ }^{5}$ Lindsay et al. ${ }^{8}$ found that golfers with LBP demonstrated significantly less trunk rotator endurance capacity than that of healthy golfers and control subjects. A longitudinal prospective study determined that professional golfers were at risk of sustaining a low back injury if they demonstrated a lateral endurance test performance difference greater than a 12.5 seconds between sides, body mass index less than $25.7 \mathrm{~kg} / \mathrm{m}^{2}$, and reduced hip flexor length) ${ }^{6}$

\section{Evaluating Functional Core Strength and Initial Treatment Strategies}

A thorough musculoskeletal examination should be performed to identify each patient's unique functional limitations. To evaluate a golfer's core endurance capacity, the core endurance functional tests as advocated by McGill $^{13}$ are recommended. Core endurance capacity is assessed by timing the golfer's ability to maintain each of three test positions: (a) the lateral musculature test performed on each side, (b) the flexor endurance test, and (c) the back extensor test. Total endurance capacity and ratios between the tests help to identify dysfunctional components. '

McGill $^{13}$ advocates an initial rehabilitation strategy to improve the endurance capacity of the core musculature in those who have suffered a low back injury. Along with development of fatigue resistance, immediate rehabilitation interventions should be focused on normalization of any side-to-side flexibility difference. Table 1 presents the components of the initial phase of a return to golf rehabilitation program that is designed to improve core musculature endurance capacity and achieve optimal ratios between groups of muscles. A guide for progression is to first teach awareness of spine position and specific muscle activation, followed by implementation of stabilization activities that build core musculature endurance and establish motor activation patterns and then reinforcing proper muscle activation patterns during functional activities. ${ }^{13}$

\begin{tabular}{l}
$\begin{array}{l}\text { TABLE 1. INITIAL CORE ENDURANCE } \\
\text { PROGRAM TO IMPROVE CORE ENDUR- } \\
\text { ANCE CAPACITY }\end{array}$ \\
$\begin{array}{l}\text { Bird dog } \\
\text { Side planks }\end{array}$ \\
$\begin{array}{l}\text { Crunches } \\
\text { Front planks }\end{array}$ \\
\hline
\end{tabular}

\section{Functional Golf Core Training}

Once the patient demonstrates improved core endurance scores (Table 2), progression can be made to a functional core conditioning program. Inclusion of functional core exercises is a key to optimal recovery. The golfer's core muscles are responsible for dual roles of creating torso rotation and stabilizing (protecting) the spine from injurious forces. ${ }^{14} \mathrm{~A}$ variety of exercises should be performed, because trunk stabilization requires proper activation of multiple muscle groups. ${ }^{15}$ The exercises utilized in this phase of the rehabilitation program should reproduce functional movement patterns. Some exercises are not appropriate for all individuals. Discretion should be used based on the individual athlete when selecting exercises for golf performance and rehabilitation.

Exercises that challenge a golfer's ability to stabilize his or her spine while incorporating functional movement patterns include the lunge twist, the prone twist (Figure 1), the Russian twist (Figures $2 \& 3$ ), and kettle ball squats (Figures $4 \& 5$ ). Table 3 presents a sample advanced functional core rehabilitation program and Table 4 presents a description of each exercise.

\section{Including Plyometrics in a Strength Training Program}

When the golfer's symptoms have resolved and endurance and strength have been restored, plyometric training should be included in the rehabilitation program. Research has demonstrated that the integration of plyometrics increases club head velocity (CHV) and driving distance (DD). ${ }^{16,17}$ Plyometric training may also help to protect the body from potentially injuri- 

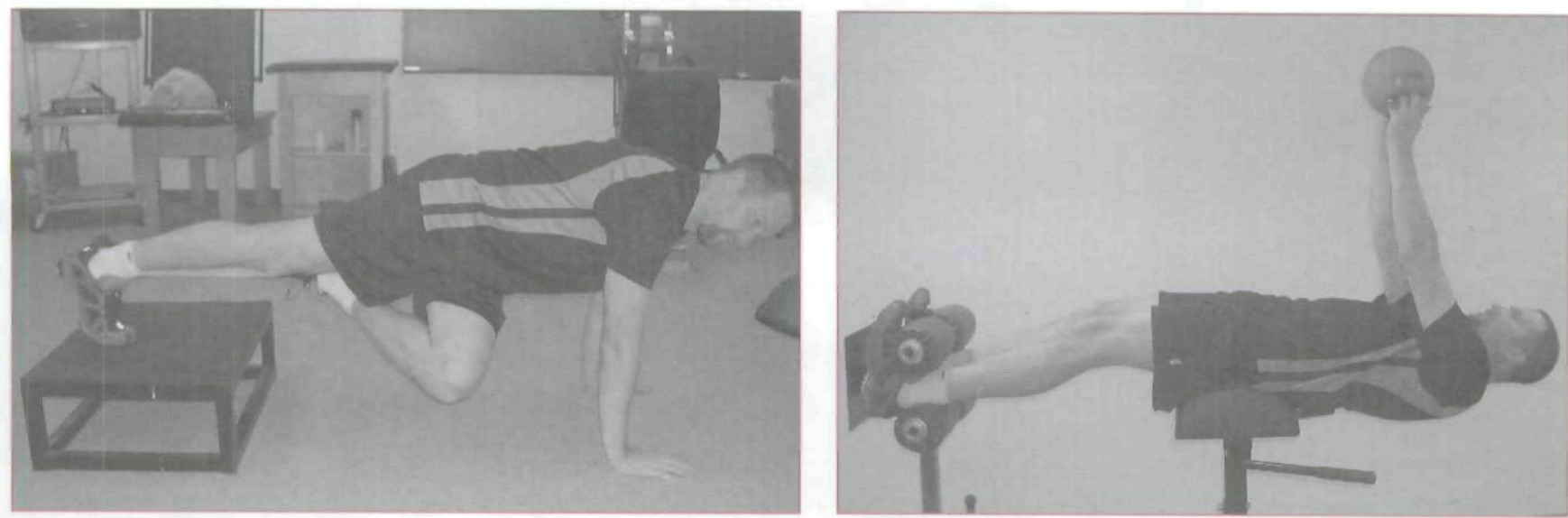

Figure I Prone twist.

Figure 2 Starting position for the Russian twist.

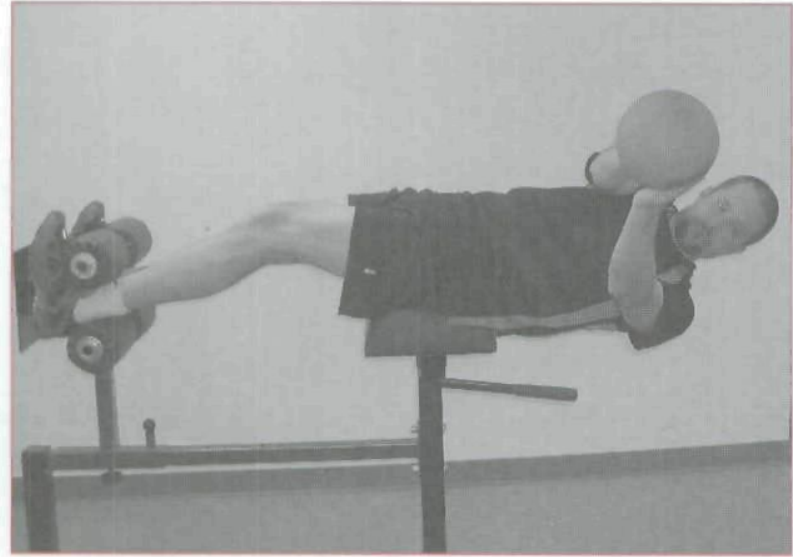

Figure 3 Ending position for the Russian twist.

TABLE 2. PROTECTIVE ENDURANCE RATIOS 1.3

$\begin{array}{ll}\begin{array}{l}\text { Right lateral endurance score/ left lateral } \\ \text { endurance score }\end{array} & >0.05 \\ \begin{array}{l}\text { Lateral endurance score (either side)/ back } \\ \text { extensor test score }\end{array} & >0.75 \\ \begin{array}{l}\text { Flexor endurance test score/ back extensor } \\ \text { test score }\end{array} & >1.0\end{array}$

ous forces, thereby reducing the risk of golf-related injury. Standing and seated medicine ball throws have been shown to improve CHV and DD. ${ }^{16}$ The program presented in Table 5 may be performed once or twice per week, with 48-72 hours of rest between sessions. The athlete to should be allowed to rest for 1-5 minutes between each exercise. ${ }^{18}$

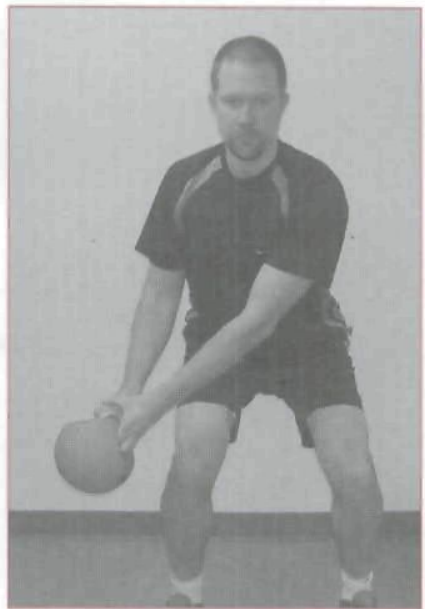

Figure 4 Starting position for the kettle-bell squats.

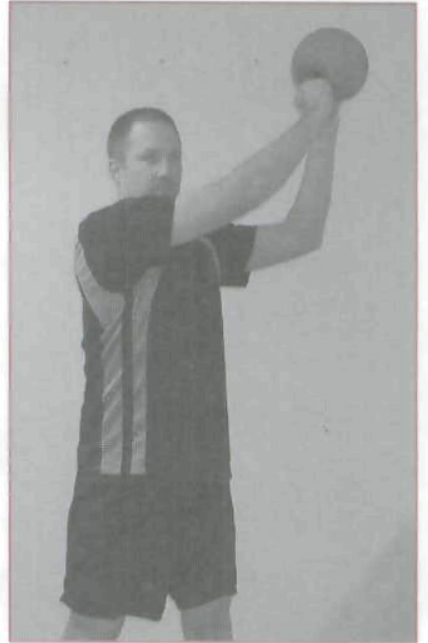

Figure 5 Ending position for the kettle-bell squats

\begin{tabular}{|c|c|c|}
\hline \multicolumn{3}{|c|}{$\begin{array}{c}\text { TABLE 3. ADVANCED FUNCTIONAL } \\
\text { CORE TRAINING PROGRAM }\end{array}$} \\
\hline Exercise & Sets & Repetitions \\
\hline Hang twist & 2 & 15 \\
\hline Lunge twist & 2 & 15 \\
\hline Prone twist & 2 & 15 \\
\hline Roman twist & 2 & $15-20$ \\
\hline Russian twist & 2 & $15-20$ \\
\hline Lat pull down & 3 & $4-6$ \\
\hline Kettle ball squats & 2 & 15 \\
\hline
\end{tabular}

Note. An abdominal bracing maneuver should be performed with each exercise. Instruct your athlete/client to co-contract both the abdominals and lower back muscles, making the muscles stiff without creating any movement of the abdominal wall. 


\section{TABLE 4. DESCRIPTION OF GOLFER'S ADVANCED CORE TRAINING EXERCISES}

\begin{tabular}{|c|c|}
\hline uercise & Technique \\
\hline Hang twist & $\begin{array}{l}\text { Grip a pull up bar or the top of a squat rack with a supinated grip bilaterally. Raise the knees toward the } \\
\text { right shoulder until thighs are parallel with the floor. Hold for } 1 \text { to } 2 \text { counts, then lower and repeat to } \\
\text { the opposite side. }\end{array}$ \\
\hline Lunge twist & $\begin{array}{l}\text { While performing the classic lunge exercise, rotate your trunk toward the side of your rear leg. Return } \\
\text { to the start position and repeat to the opposite side. A stick can be used to help balance. }\end{array}$ \\
\hline $\begin{array}{l}\text { Prone twist } \\
\text { (Figure 1) }\end{array}$ & $\begin{array}{l}\text { Start with both feet supported on a bench and both hands positioned on the floor, shoulder width } \\
\text { apart. Bend one knee to waist height and then rotate the trunk toward the opposite side. Hold up to } 5 \\
\text { seconds. Switch legs and repeat to the opposite side. }\end{array}$ \\
\hline Roman twist & $\begin{array}{l}\text { Incorporating a twisting motion with a roman chair exercise will increase the challenge to the oblique } \\
\text { muscles improving trunk stabilization capacity. }\end{array}$ \\
\hline $\begin{array}{l}\text { Russian twist } \\
\text { (Figures } 2 \\
\text { and 3) }\end{array}$ & $\begin{array}{l}\text { Position yourself on the roman chair as shown. While maintaining the abdominal bracing contraction, } \\
\text { slowly rotate your trunk and arms to the side. Hold for up to } 5 \text { seconds. Return to the start position and } \\
\text { repeat to the opposite side. To increase the intensity, hold a medicine ball out with straight arms. }\end{array}$ \\
\hline Lat pull down & $\begin{array}{l}\text { The latissimus dorsi provides power during the forward swing and acceleration phases of the golf } \\
\text { swing. Since this muscle is used to provide power, it should be trained with low repetitions and heavy } \\
\text { weights. }\end{array}$ \\
\hline $\begin{array}{l}\text { Kettle ball } \\
\text { squats (Fig- } \\
\text { ures } 4 \text { and } 5 \text { ) }\end{array}$ & $\begin{array}{l}\text { Squat and rotate to grab a kettle ball positioned to the outside of your right foot. As you stand up from } \\
\text { the squat position, rotate the kettle ball in a diagonal position across your body to above the left shoul- } \\
\text { der. Repeat this pattern to each side. }\end{array}$ \\
\hline $\begin{array}{l}\text { Standing and } \\
\text { seated hori- } \\
\text { zontal throws }\end{array}$ & $\begin{array}{l}\text { Position yourself perpendicular to a rebounder approximately } 8-10 \text { feet away. While standing or in } \\
\text { a seated position, throw a light plyoball or medicine ball across your body toward the rebounder. As } \\
\text { the ball rebounds back to you, catch it, and quickly throw it back toward the rebounder. Repeat this } \\
\text { sequence for the desired number of repetitions. When sitting on a physioball, maintain an upright, neu- } \\
\text { tral spine posture. }\end{array}$ \\
\hline
\end{tabular}

\begin{tabular}{l} 
TABLE 5. BASIC PLYOMETRIC \\
TRAINING PROGRAM FOR GOLFERS \\
$\begin{array}{l}\text { Standing horizontal throws (each } \\
\text { side) }\end{array}$ \\
$\begin{array}{l}\text { Seated horizontal throws (each } \\
\text { side) }\end{array}$ \\
$\begin{array}{l}\text { Overhead ball throw } \\
\text { O-3 sets } \times 10 \text { reps }\end{array}$ \\
\hline
\end{tabular}

\section{Swing Considerations}

A golfer with chronic LBP may have a faulty swing pattern that imposes stress on the lumbar spine. Referral to a professional golf instructor may help to ensure that a faulty swing pattern does not continually exacerbate low back symptoms. Bulbulian et al. ${ }^{19}$ have suggested that a shortened backswing reduces stress to the low back and does not necessarily diminish CHV. Pre- liminary data from our lab agrees with the finding of McGill ${ }^{13}$ that $\mathrm{CHV}$ is marginally reduced, but the effect on performance is minimal in relation to the benefit that the golfer may derive in terms of the ability to participate in the game. Another option is to consider a different swing type, such as the two-plane swing described by Hardy. ${ }^{20}$ The two-plane swing is believed to minimize trunk and hip dissociation and the " $\mathrm{x}$ factor" compared to the one-plane swing, although no definitive studies have substantiated this claim.

\section{Conclusion}

A comprehensive rehabilitation approach for golfers with LBP should include the prescription of functional core exercises and the referral to a professional golf instructor. Successful return of a golfer with LBP to sport depends on identification of core dysfunctions and implementation of exercises that address them. 


\section{References}

1. McHardy A, Pollard H, Luo K. Golf injuries: a review of the literature. Sports Med. 2006;36(2):171-187.

2. Hosea TM, Gatt CJ. Jr. Back pain in golf. Clin Sports Med. Jan 1996:15(1):37-53.

3. Fradkin AJ, Cameron PA, Gabbe BJ. Golf injuries-common and potentially avoidable. J Sci Med Sport, 2005;8(2):163-170.

4. Coleman SG, Rankin AJ. A three-dimensional examination of the planar nature of the golf swing. J Sports Sci. 2005:23(3):227-234.

5. Evans C, Oldreive W. A study to investigate whether golfers with a history of low back pain show a reduced endurance of transversus abdominis. J Manipulative Physiol Ther. 2000;8(4):162-174.

6. Evans K, Refshauge K, Adams R, Aliprandi L. Predictors of low back pain in young elite golfers: a preliminary study. Phys Ther Sport 2005:6(3):122-130

7. Vad VB, Bhat AL, Basrai D, Gebeh A, Aspergren DD, Andrews JR Low back pain in professional golfers: the role of associated hip and low back range-of-motion deficits. Am J Sports Med. 2004;32(2):494497

8. Lindsay D. Horton I. Trunk rotation strength and endurance in healthy normals and elite male golfers with and without low back pain. NAJSPT. 2006;1 (2):80-89

9. Lindsay D. Horton J. Comparison of spine motion in elite golfers with and without low back pain. J Sports Sci. 2002:20(8):599-606

10. Hides JA, Richardson CA, Jull GA. Multifidus muscle recovery is not automatic after resolution of acute, first-episode low back pain. Spine. 1996:21 (23):2763-2769

11. Hides JA, Stokes MJ, Saide M, Jull GA, Cooper DH. Evidence of lumbar multifidus muscle wasting ipsilateral to symptoms in patients with acute/subacute low back pain. Spine. 1994:19(2):165-172.

12. Cassisi JE, Robinson ME, O'Conner P, MacMillan M. Trunk strength and lumbar paraspinal muscle activity during isometric exercise in chronic low-back pain patients and controls. Spine. 1993:18(2):245251

13. McGill S. Low Back Disorders: Evidence-Based Prevention and Rehabilitation. Champaign, IL: Human Kinetics; 2002

14. Pink M, Perry J, Jobe FW. Electromyographic analysis of the trunk in golfers. Am J Sports Med. May-Jun 1993;21 (3):385-388

15. Kavcic N, Grenier S, McGill SM. Determining the stabilizing role of individual torso muscles during rehabilitation exercises. Spine. 2004;29(11):1254-1265

16. Doan B, Newton R, Kwon Y, Kraemer W. Effects of physical conditioning on intercollegiate golfer performance. J Strength Cond Res. 2006;20(1):62-72

17. Fletcher I, Hartwell M. Effect of an 8-week combined weights and plyometric training program on golf drive performance. $J$ Strength Cond Res. 2004:18(1):59-62.

18. Chu D. Jumping Into Plyometrics. 2nd ed. Champaign, IL: Human Kinetics; 1998

19. Bulbulian R, Ball KA, Seaman DR. The short golf backswing: effects on performance and spinal health implications. J Manipulative Physiol Ther. 2001;24(9):569-575

20. Hardy J. Andrisani J. Plane Truth For Golfers: Breaking Down The Oneplane Swing And The Two-plane Swing And Finding The One That's Right For You. New York: McGraw-Hill; 2005

Jason Brumitt is an athletic trainer and a board certified sports physical therapist. He is an instructor of physical therapy at Pacific University in Hillsboro, OR. He provides clinical rehabilitation services to the university's injured athletes.

R. Barry Dale is an assistant professor in the Physical Therapy Department at the University of Tennessee at Chattanooga. His teaching and research areas are related to exercise physiology and orthopedic sport rehabilitation.

\section{Study fundamental human movement using a quantitative biomechanical analysis}

\section{Biomechanical finalusis of Fundamental Human movements}

firthur $\mathrm{E}$. Chapman

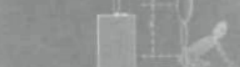

\section{R} variations. Each activity is analyzed using a specific seven-point format that helps readers identify the biomechanical concepts that explain how the movements are made and how they can be modified to correct problems. The seven points for analysis are aim, mechanics, biomechanics, variations, enhancement, safety, and practical examples that move from the simple to the more complex.

Superbly illustrated with more than 140 figures depicting the critical points of biomechanical analysis, this text is an invaluable tool for those pursuing the study of advanced quantitative biomechanics.

C) $2008 \cdot$ Hardback $\bullet 320 \mathrm{pp}$

ISBN 978-0-7360-6402-6

$\$ 79.00(\$ 86.95 \mathrm{CDN}$

E45.00 UK, €67.50 EURO,

$\$ 117.70$ AUS, $\$ 144.00 \mathrm{NZ}$ )*

\section{College Instructors:}

To request an exam copy, please visit our Web site at www.HumanKinetics.com/faculty.
HUMAN KINETICS

The Information Leader in Physical Activity

P.O. Box 5076 • Champaign, IL 61825-5076 USA
For a complete description or to order, call:

(800) 747-4457 US • (800) 465-7301 CDN • 44 (0) 113-255-5665 UK (08) 8372-0999 AUS • (09) 448-1207 NZ • (217) 351-5076 International Or visit www. HumanKinetics.com! 
Copyright of Athletic Therapy Today is the property of Human Kinetics Publishers, Inc. and its content may not be copied or emailed to multiple sites or posted to a listserv without the copyright holder's express written permission. However, users may print, download, or email articles for individual use. 